\title{
An Interrupted Continuum of Care? What are the Risk Factors and Comorbidities Related to Long-Term Engagement and Retention in HIV Care?
}

\author{
Mari-Lynn Drainoni ${ }^{1-3^{*}}$, Kathleen M. Carey ${ }^{1,3}$, Jake R Morgan ${ }^{4}$, Cindy L. Christiansen ${ }^{1,3}$ M Maya McDoom ${ }^{5,6}$, Monica Malowney and Meg \\ Sullivan ${ }^{2}$
}

${ }^{1}$ Department of Health Policy \& Management, Boston University School of Public Health, Boston, USA

${ }^{2}$ Section of Infectious Diseases, Boston University School of Medicine, Boston, USA

${ }^{3}$ Center for Healthcare Organization and Implementation Research, ENRM Veterans Administration Hospital

${ }^{4}$ HIV Epidemiology and Outcomes Research Unit, Boston Medical Center, Boston, USA

${ }^{5}$ Social Science Research Center, Mississippi State University, USA

${ }^{6}$ Department of Global Health and Population, Harvard T.H. Chan School of Public Health, Boston, USA

${ }^{7}$ Department of Population Health, Maimonides Medical Center, USA

\begin{abstract}
Despite the importance of continuous care, a large proportion of persons with HIV are not engaged or retained in care at any one time, leading to poor outcomes. Identifying the risk factors associated with lack of engagement and retention in HIV care is needed in order to target patients for interventions. While both engagement and retention in care have been studied using multiple measures, the observation period for the majority of studies is less than one year, few studies have examined both initial engagement and retention, and the effect of comorbidities has typically not been included. This study extends the literature by examining how comorbidities, in addition to demographics, HIV clinical indicators and transmission risk factors, were associated with engagement and retention in a cohort study of 485 HIV-infected persons seen for an initial HIV visit at an urban safety-net hospital. Using the electronic medical record, demographic, risk factor, health status and comorbidity data were gathered at the time of initial visits. To measure engagement and retention, appointment data were obtained for a 24-month period following the initial visit. Key findings were that unknown HIV transmission risk factor and being homeless at initial visit were associated with both lack of engagement and retention. Conversely being diagnosed with a psychiatric disorder was predictive of retention. Our findings have important implications for program structure, including the integration of care, as well as regarding key components to be addressed holistically in early clinic visits.
\end{abstract}

Keywords: HIV; Safety net providers; Continuity of care; Care models

\section{Introduction}

Widespread access to combination antiretroviral therapy (cART) has transformed HIV into a chronic, manageable disease, drastically lowering HIV-related morbidity and mortality [1-4].Yet recent estimates suggest that little over half of those diagnosed with HIV may be engaged in and retained in care at any one time [5-9]. Studies have shown that HIV-infected persons who are not consistently engaged in care have only intermittent access to cART or to other medical and psychiatric services, and consequently have poorer outcomes including greater numbers of hospitalizations and increased mortality $[1,2,6,10,11]$ Moreover, from a public health perspective, individuals without regular access to cART may continue to transmit HIV in the community due to ongoing viremia $[1,11,12]$. Therefore, identifying the risk factors associated with inability to initially engage in as well as stay in HIV care is needed in order to target patients for interventions that can ultimately lead to improved clinical status, lower mortality, and reduced transmission of disease $[6,9,13,14]$.

Studies of participation in HIV care are complicated with patients often demonstrating care patterns that include cycling in and out of care over time [15]. The literature contains a range of measures of engagement and retention [16,17]; however, the observation period for the majority of studies is less than one year, a small interval for assessing retention in care for a disease that requires chronic lifetime management [9]. Moreover, only a small number of studies have examined both initial engagement and ongoing retention in HIV care simultaneously $[6,8]$. In addition, while many studies of engagement and retention have included HIV clinical indicators and transmission risk factors, comorbidities have typically not been included. The current study extends the literature by examining how comorbidities, in addition to demographics, HIV clinical indicators and transmission risk factors, are associated with engagement and retention in a single clinic cohort study of HIV-infected persons seen for care at an urban safety-net hospital over a 24 month-period. Information available from single sites allows for more detailed knowledge of patients and of the care received [19], including comorbid health conditions frequently present in HIV-infected persons. In this study, we first examined demographic, clinical, and comorbidity characteristics of patients who successfully engaged in care delivery compared to those who failed to initially engage. We expected that patients who were never engaged in care would have unique factors affecting their probability of engagement. Moreover, these factors would be different from those associated with patients who had been initially engaged in care to

*Corresponding author: Mari-Lynn Drainoni, Boston University School of Public Health, 715 AlbanyStreet,T3W, Boston, MA 02118, USA, Tel: 617-414-1417; E-mail: drainoni@bu.edu

Received April 23, 2015; Accepted May 29, 2015; Published June 07, 2015

Citation: Drainoni M, Carey KM, Morgan JR, Christiansen CL, McDoom MM, et al. (2015) An Interrupted Continuum of Care? What are the Risk Factors and Comorbidities Related to Long-Term Engagement and Retention in HIV Care?. J AIDS Clin Res 6: 468. doi:10.4172/2155-6113.1000468

Copyright: (c) 2015 Drainoni M, et al. This is an open-access article distributed under the terms of the Creative Commons Attribution License, which permits unrestricted use, distribution, and reproduction in any medium, provided the original author and source are credited. 
Citation: Drainoni M, Carey KM, Morgan JR, Christiansen CL, McDoom M M, et al. (2015) An Interrupted Continuum of Care? What are the Risk Factors and Comorbidities Related to Long-Term Engagement and Retention in HIV Care?. J AIDS Clin Res 6: 468. doi:10.4172/21556113.1000468

Page 2 of 6

experience an interruption in the future. Hence in a second step, we identified which of these characteristics were associated with longerterm retention in care.

\section{Methods}

\section{Data source and study sample}

We conducted a retrospective cohort study of patients new to care at the HIV clinic of a large urban medical center located in the northeast U.S. Data on demographic and clinical characteristics of patients were drawn from electronic medical records (EMR) collected at the medical center. Patients were eligible for inclusion in the study if they were HIV-positive and were seen for an initial visit for HIV primary care with a physician in the clinic between April 1, 2007 and September 1, 2010. Patients were identified as new to care if they had no prior visits to the clinic or had not had a visit with a physician to the clinic in the three years prior to the initial visit. The window of observation on each patient was 24 months, beginning at the date of the initial visit. The patient cohort consisted of 485 individual patients. HIV care in this study was operationalized as attendance at HIV primary care visits, a commonly used method in prior studies $[2,4,17]$. As described below, we then used different measures of time and number of appointments kept to define engagement and retention in care.

\section{Definitions of outcome variables}

For our initial analyses, the outcome variable was engaged in care. In our cohort, we observed different overall utilization patterns within the first three months of initiating care, and we therefore created the engaged in care variable according to utilization during the first three months of care. We coded patients as engaged if they had at least one follow-up visit with a physician in the first three months of their observation period in addition to the initial physician visit. Patients who did not return for care within three months of the initial visit were coded as not engaged.

The second outcome variable was retention in care. We applied one definition used in previous literature to create the retention in care variable, defining a gap in care (not retained) as 180 days or more occurring between two primary care visits [20]. If there was a period of time during the 24-month observation period in which a patient had more than 180 days between two visits, that patient was recorded to have a significant interruption or a "gap" in care.

\section{Covariates}

Covariates included several demographic variables: age, gender, race/ethnicity, housing status, and self-reported HIV transmission risk category. Transmission risk categories included heterosexual, men who have sex with men (MSM), intravenous drug use (IDU, including MSM IDU), other risk, and unknown risk. Clinical covariates consisted of three HIV-related variables: CD4 cell count, detectable viral load (VL) (>200), and whether the patient indicated being on cART at the initial visit. In terms of comorbid conditions, we included indicator variables for comorbidities frequently present in HIV-infected persons: the presence of an AIDS-defining illness (ADI); sexually transmitted infections (STI); psychiatric conditions including depression, mood and anxiety disorders and cognitive impairment; substance abuse disorders and hepatitis (A, B or C). Other specific health conditions included as an any other comorbidity variable included cancer, cardiovascular disease, diabetes, pulmonary disease and renal disease. All covariates were based on data available at the index HIV primary care visit.

\section{Statistical analysis}

In order to determine factors associated with engagement in care, we conducted bivariate analyses using chi-square tests or t-tests for continuous variables. Next, we used multivariable logistic regression analysis, controlling for all characteristics simultaneously, to predict engagement in care. Our second analysis focused on identifying those characteristics that predicted retention in care. Using "no six month gaps in care" as the outcome variable measuring retention in care, we repeated the bivariate and multivariable analyses. We compared patients who had no gaps in care to those who had at least one gap in care in the bivariate models, and performed logistic regression to predict the probability of retention in care. We also conducted sensitivity analyses using several different gap-in-care models. All analyses were performed using the statistical software Stata (Version 12). The study was approved by the Boston University Medical Center Institutional Review Board.

\section{Results \\ Description of the study sample}

Among the 485 patients studied, the majority were male (58\%) and persons of color, including 55\% Black and $21 \%$ Latino/a. The sample had a mean age of 42 . The cohort were housed at the time of enrollment (82\%) although $17 \%$ indicated being homeless. The most common HIV risk category was heterosexual transmission (48\%), followed by $22 \%$ identifying as men who have sex with men (MSM) and $18 \%$ injection drug use (IDU). Notably, the transmission risk factor of $8 \%$ of patients was unknown at the time of initial visit. In terms of comorbidities commonly considered "related" to HIV, $5 \%$ were documented to have an AIDS-defining illness (ADI), $11 \%$ a sexually transmitted infection (STI), $8 \%$ hepatitis (A, B or C), $12 \%$ a psychiatric disorder, and $11 \%$ a substance use disorder. In addition, $18 \%$ were documented as having at least one additional health condition, as defined above. Most patients were not on cART at their first visit (62\%). Only $20 \%$ had an undetectable viral load at initial visit and $12 \%$ had a CD 4 count below $200 \mathrm{ml} /$ copy at that time. Additionally, the CD4 counts and VLs were unknown for over $40 \%$ of the overall sample.

\section{Engagement in care}

Overall, 397 ( $82 \%$ of the full cohort) established care according to our measure of engagement. Table 1 presents the results of bivariate analyses comparing the 397 engaged patients with the 88 patients (18\%) who were not engaged within three months after the initial visit. The two groups did not vary significantly on age, gender, or race. However, there was a significant difference in housing status: among those not engaged in care, $30 \%$ were homeless compared to $14 \%$ of engaged patients $(\mathrm{p}<0.01)$. HIV transmission risk factor also differed statistically between the two groups, notably for the categories heterosexual $(51 \%$ engaged compared to $35 \%$ not engaged), IDU (17\% engaged compared to $23 \%$ not engaged), and unknown (7\% engaged compared to $15 \%$ not engaged) $(\mathrm{p}=0.01)$. Among the HIV-related clinical variables, the groups differed according to whether they were on cART and the presence of detectable VL at initial visit. The not engaged group had both a higher proportion of individuals on cART (48\% compared to $35 \%, \mathrm{p}=0.03)$ and with undetectable VL (31\% compared to $18 \%$, $\mathrm{p}<0.01)$. In terms of comorbidities, patients with a history of ADIs at 
Citation: Drainoni M, Carey KM, Morgan JR, Christiansen CL, McDoom M M, et al. (2015) An Interrupted Continuum of Care? What are the Risk Factors and Comorbidities Related to Long-Term Engagement and Retention in HIV Care?. J AIDS Clin Res 6: 468. doi:10.4172/21556113.1000468

Page 3 of 6

\begin{tabular}{|c|c|c|c|c|c|}
\hline \multirow[t]{2}{*}{ 'Characteristic } & \multicolumn{2}{|c|}{$\begin{array}{l}\text { Not Engaged } \\
\quad(n=88)\end{array}$} & \multicolumn{2}{|c|}{$\begin{array}{c}\text { Engaged } \\
(n=397)\end{array}$} & \multirow[t]{2}{*}{$p$-value } \\
\hline & $\mathrm{n}$ & $\%$ & $\mathrm{n}$ & $\%$ & \\
\hline Female & 37 & $42 \%$ & 165 & $42 \%$ & \multirow{2}{*}{0.93} \\
\hline Male & 51 & $58 \%$ & 232 & $58 \%$ & \\
\hline White & 24 & $27 \%$ & 78 & $20 \%$ & \multirow{4}{*}{0.27} \\
\hline Other/ Unknown Race & 2 & $2 \%$ & 10 & $3 \%$ & \\
\hline Black & 41 & $47 \%$ & 226 & $57 \%$ & \\
\hline Hispanic & 21 & $24 \%$ & 83 & $21 \%$ & \\
\hline Housing & 61 & $69 \%$ & 339 & $85 \%$ & \multirow{3}{*}{$<0.01$} \\
\hline Homeless & 26 & $30 \%$ & 56 & $14 \%$ & \\
\hline Unknown Housing & 1 & $1 \%$ & 2 & $1 \%$ & \\
\hline Heterosexual & 31 & $35 \%$ & 204 & $51 \%$ & \multirow{5}{*}{0.01} \\
\hline Other Risk & 5 & $6 \%$ & 11 & $3 \%$ & \\
\hline Unknown Risk & 13 & $15 \%$ & 26 & $7 \%$ & \\
\hline MSM & 19 & $22 \%$ & 90 & $23 \%$ & \\
\hline IDU (incl MSM IDU) & 20 & $23 \%$ & 66 & $17 \%$ & \\
\hline Mean age & 40.5 & NA & 42.4 & NA & 0.13 \\
\hline On ART Baseline & 42 & $48 \%$ & 140 & $35 \%$ & 0.03 \\
\hline VL undetectable & 27 & $31 \%$ & 72 & $18 \%$ & \multirow{3}{*}{0.01} \\
\hline VL detectable & 23 & $26 \%$ & 153 & $39 \%$ & \\
\hline VL unknown at first visit & 38 & $43 \%$ & 172 & $43 \%$ & \\
\hline CD4 over 200 & 40 & $45 \%$ & 166 & $42 \%$ & \multirow{3}{*}{0.80} \\
\hline CD4 $<200$ & 11 & $13 \%$ & 49 & $12 \%$ & \\
\hline CD4 unknown at first visit & 37 & $42 \%$ & 182 & $46 \%$ & \\
\hline ADI & 9 & $10 \%$ & 16 & $4 \%$ & 0.02 \\
\hline Hepatitis A, B, or C & 11 & $13 \%$ & 26 & $7 \%$ & 0.06 \\
\hline Other Medical Comorbidity & 16 & $16 \%$ & 72 & $18 \%$ & 0.62 \\
\hline Psychiatric Disorder & 12 & $14 \%$ & 47 & $12 \%$ & 0.64 \\
\hline STI & 14 & $16 \%$ & 39 & $10 \%$ & 0.10 \\
\hline Substance Use Disorder & 10 & $11 \%$ & 44 & $11 \%$ & 0.94 \\
\hline
\end{tabular}

Table 1: Characteristics of Patients Engaged and Not Engaged in Care $(n=485)$

baseline were less likely to engage in care than patients without ADIs ( $10 \%$ compared to $4 \%, \mathrm{p}=0.02$ ).

Table 2 presents the results of the logistic regression in which engaged in care is the outcome variable. Older age was associated with higher odds (1.03) of engagement (95\% CI, 1.01-1.06; $\mathrm{p}=0.02$ ). Persons with a detectable VL were more than twice as likely (2.64) to be engaged in care $(95 \% \mathrm{CI}, 1.18-5.94 ; \mathrm{p}=0.02)$ than those with an undetectable VL. Persons with an unknown transmission risk category had substantially lower odds of engagement: (0.43) (95\% CI, 0.19-1.01; $\mathrm{p}=0.05)$ relative to those whose transmission risk was heterosexual. Homelessness was also associated with lower odds $(0.49)$ of engagement (95\% CI, 0.26-0.92; $\mathrm{p}=0.03$ ). Among comorbidities, only the presence of an ADI was associated with engagement, as persons with ADIs were less likely (0.37) to be engaged in care (95\% CI, 0.13-1.01; $\mathrm{p}=0.05)$.

\section{Retention in care}

Table 3 presents results for bivariate analyses comparing individuals who were retained (no gap in care) with those who were not retained (had any gap in care). In terms of retention, $27 \%$ of the sample $(n=130)$ was fully retained over the 24 -month period of review, while $73 \%(n=355)$ had at least one gap in care. The retained and not retained groups were significantly different in terms of housing status, transmission risk factor, presence of a psychiatric disorder, and CD4 count and VL at initial visit. Persons who were homeless were more likely to have a gap in care (20\% of not retained compared to $9 \%$ of retained, $\mathrm{p}=0.001$ ), and persons with an unknown transmission risk factor were also more likely not to be retained ( $10 \%$ compared to $2 \%$ of retained, $\mathrm{p}=0.01$ ). Persons whose viral load was unknown at the initial visit were more likely to be retained ( $52 \%$ compared to $40 \%, \mathrm{p}=0.03$ ), as were persons with an unknown CD4 count (55\% compared to $41 \%$, $\mathrm{p}=0.01$ ). Finally, having a psychiatric disorder documented in the EMR was associated with retention ( $17 \%$ compared to $10 \%, \mathrm{p}=0.05$ ).

In Table 4 , we present the results of the multivariable logistic regression with the outcome of retention (no gap in care). Housing status, transmission risk factor and psychiatric diagnosis were statistically significant. Individuals who were homeless had less than half the odds $(0.43)$ of being retained in care than those who were housed (95\% CI, 0.21-0.89; $\mathrm{p}=0.02$ ) and persons with an unknown transmission risk factor $(0.18 ; 95 \% \mathrm{CI}, 0.05-0.64 ; \mathrm{p}=0.01)$ were far less likely to be retained in care compared to those with heterosexual risk. Persons diagnosed with a psychiatric disorder were almost three times more likely (2.65) to be retained in care compared to those without a psychiatric disorder (95\% CI, 1.27-5.51; $\mathrm{p}=0.01$ ). Results of sensitivity analysis using different gap-in-care models yielded similar results to those reported in Tables 3 and 4. 
Citation: Drainoni M, Carey KM, Morgan JR, Christiansen CL, McDoom M M, et al. (2015) An Interrupted Continuum of Care? What are the Risk Factors and Comorbidities Related to Long-Term Engagement and Retention in HIV Care?. J AIDS Clin Res 6: 468. doi:10.4172/21556113.1000468

Page 4 of 6

\begin{tabular}{|c|c|c|c|c|}
\hline \multirow{3}{*}{\begin{tabular}{|l} 
Characteristic \\
Female \\
\end{tabular}} & \multicolumn{2}{|c|}{ Engaged } & & \\
\hline & \multirow{2}{*}{$\begin{array}{l}\text { OR } \\
1.00\end{array}$} & \multirow{2}{*}{$\begin{array}{c}\text { p-value } \\
\text { Ref. }\end{array}$} & \multicolumn{2}{|c|}{$95 \% \mathrm{Cl}$} \\
\hline & & & & \\
\hline Male & 1.05 & 0.86 & 0.58 & 1.90 \\
\hline White & 1.00 & Ref. & & \\
\hline Other/Unknown Race & 1.59 & 0.59 & 0.30 & 8.48 \\
\hline Black & 1.25 & 0.52 & 0.63 & 2.49 \\
\hline Hispanic & 1.18 & 0.67 & 0.56 & 2.50 \\
\hline Housing & 1.00 & Ref. & & \\
\hline Homeless & 0.49 & 0.03 & 0.26 & 0.92 \\
\hline Unknown Housing & 0.43 & 0.53 & 0.03 & 5.88 \\
\hline Heterosexual & 1.00 & Ref. & & \\
\hline Other Risk & 0.33 & 0.08 & 0.09 & 1.12 \\
\hline Unknown Risk & 0.43 & 0.05 & 0.19 & 1.01 \\
\hline MSM & 0.85 & 0.69 & 0.38 & 1.90 \\
\hline IDU (incl MSM IDU) & 0.63 & 0.24 & 0.29 & 1.37 \\
\hline On ART Baseline & 0.96 & 0.90 & 0.53 & 1.76 \\
\hline Age & 1.03 & 0.02 & 1.01 & 1.06 \\
\hline VL undetectable & 1.00 & Ref. & & \\
\hline VL detectable & 2.64 & 0.02 & 1.18 & 5.94 \\
\hline VL unknown at first visit & 1.10 & 0.87 & 0.37 & 3.24 \\
\hline CD4 over 200 & 1.00 & Ref. & & \\
\hline CD4<200 & 0.76 & 0.52 & 0.33 & 1.75 \\
\hline CD4 unknown at first visit & 1.77 & 0.27 & 0.65 & 4.80 \\
\hline ADI & 0.37 & 0.05 & 0.13 & 1.01 \\
\hline Medical Comorbidities 1+ & 1.05 & 0.89 & 0.49 & 2.25 \\
\hline Hepatitis A, B, or C & 0.56 & 0.23 & 0.22 & 1.45 \\
\hline Psychiatric Disorder & 0.83 & 0.67 & 0.36 & 1.94 \\
\hline STI & 0.66 & 0.30 & 0.31 & 1.44 \\
\hline Substance Use Disorder & 2.13 & 0.14 & 0.78 & 5.82 \\
\hline
\end{tabular}

Table 2: Predictors of Engagement in Care $(n=485)$

\section{Discussion}

In this study, we examined both early engagement (two visits within the first three months) and long-term retention (no care gap of greater than 180 days over 24 months) in care among patients initiating care at an HIV clinic within a safety net urban medical center. While the large majority of patients initially engaged in care based on our definition of engagement, we found that having an unknown HIV transmission risk and having an AIDS-defining illness documented at baseline were associated with lack of engagement. When we examined retention over 24 months after the initial visit, however, just over onequarter of patients had been fully retained. In terms of retention, housing status and HIV transmission risk factor were significant, with homeless persons and persons for whom HIV transmission risk factor was unknown less likely to be retained. Conversely, being diagnosed with a psychiatric disorder was predictive of retention over 24-month observation period.

As expected with the overall life instability that can be intrinsic to homelessness and has been shown in other reports to be negatively associated with participation in HIV care [21-24] patients identified in this study as being homeless were less likely to be successfully retained in care. The lack of engagement and retention associated with an unknown HIV transmission risk factor raises the question of whether not endorsing transmission risk that may actually be a surrogate for some other factor that is creating barriers to engagement and retention. This highlights that more intensively exploring risk group with patients

\begin{tabular}{|c|c|c|c|c|c|}
\hline \multirow[t]{2}{*}{ Characteristic } & \multicolumn{2}{|c|}{$\begin{array}{c}\text { Retained } \\
(n=130)\end{array}$} & \multicolumn{2}{|c|}{$\begin{array}{l}\text { Not Retained } \\
\quad(n=355)\end{array}$} & \multirow[t]{2}{*}{$p$-value } \\
\hline & $n$ & $\%$ & $n$ & $\%$ & \\
\hline Female & 56 & $43 \%$ & 146 & $41 \%$ & \multirow{2}{*}{0.70} \\
\hline Male & 74 & $57 \%$ & 209 & $59 \%$ & \\
\hline White & 23 & $18 \%$ & 79 & $22 \%$ & \multirow{4}{*}{0.62} \\
\hline Other/Unknown Race & 2 & $2 \%$ & 10 & $3 \%$ & \\
\hline Black & 75 & $58 \%$ & 192 & $54 \%$ & \\
\hline Hispanic & 30 & $23 \%$ & 74 & $21 \%$ & \\
\hline Housing & 117 & $90 \%$ & 283 & $80 \%$ & \multirow{3}{*}{0.01} \\
\hline Homeless & 12 & $9 \%$ & 70 & $20 \%$ & \\
\hline Unknown Housing & 1 & $1 \%$ & 2 & $1 \%$ & \\
\hline Heterosexual & 71 & $55 \%$ & 164 & $46 \%$ & \multirow{5}{*}{0.01} \\
\hline Other Risk & 2 & $2 \%$ & 14 & $4 \%$ & \\
\hline Unknown Risk & 3 & $2 \%$ & 36 & $10 \%$ & \\
\hline MSM & 35 & $27 \%$ & 74 & $21 \%$ & \\
\hline IDU (incl MSM IDU) & 19 & $15 \%$ & 67 & $19 \%$ & \\
\hline Mean age & 41.1 & NA & 42.1 & NA & 0.36 \\
\hline On ART Baseline & 49 & $38 \%$ & 133 & $37 \%$ & 0.94 \\
\hline VL undetectable & 19 & $15 \%$ & 80 & $23 \%$ & \multirow{3}{*}{0.03} \\
\hline VL detectable & 43 & $33 \%$ & 133 & $37 \%$ & \\
\hline VL unknown at first visit & 68 & $52 \%$ & 142 & $40 \%$ & \\
\hline CD4 over 200 & 40 & $31 \%$ & 166 & $47 \%$ & \multirow{3}{*}{0.01} \\
\hline CD4<200 & 18 & $14 \%$ & 42 & $12 \%$ & \\
\hline CD4 unknown at first visit & 72 & $55 \%$ & 147 & $41 \%$ & \\
\hline ADI & 7 & $5 \%$ & 18 & $5 \%$ & 0.89 \\
\hline Hepatitis A, B, or C & 31 & $9 \%$ & 6 & $5 \%$ & 0.13 \\
\hline Medical Comorbidities 1+ & 62 & $17 \%$ & 24 & $18 \%$ & 0.80 \\
\hline Psychiatric Disorder & 22 & $17 \%$ & 37 & $10 \%$ & 0.05 \\
\hline STI & 16 & $12 \%$ & 37 & $10 \%$ & 0.56 \\
\hline Substance Use Disorder & 11 & $8 \%$ & 43 & $12 \%$ & 0.26 \\
\hline
\end{tabular}

* $P$-value calculated using either $x 2$ test or, for variables with expected cell counts $\leq 5$, Fisher's Exact test. The exception was age, a continuous measure, where a student's t-test was used to calculate the $\mathrm{p}$-value. The $\mathrm{n}$ column for mean age is the mean age for that patient group.

Table 3: Characteristics of Patients Retained and Not Retained in Care $(n=485)$.

at initial visit, while potentially off-putting for some, could also serve to identify areas for intervention.

The higher level of engagement among patients with detectable $\mathrm{VL}$ at baseline was unexpected, as detectable VL is typically indicative of not being on cART and thus not being engaged in care. However, our finding raises the possibility that if a patient has an undetectable viral load at baseline and thus is likely already on cART, he/she may be presumably transitioning care from another clinical site, which is widely known to create high potential for disruption in continuity of care $[19,25,26]$ While these patients may ultimately choose to return to care at the prior site, there is also the implicit risk that they may not return to care at the prior site or effectively engage at a new care site, illustrating the vulnerable time period of care transitions as an important yet not previously highlighted aspect of the HIV care continuum. However, our findings may simply be reflective of the high proportion of patients with unknown VL at baseline, many of whom could actually have a detectable VL. Either way, our findings point out the importance of intervening with all patients arriving for initial care, including those transitioning care, whether or not their VL is detectable and ensuring that all patients are maintained in care over time.

We also found that having a psychiatric diagnosis was protective in terms of retention in care. This may be due in part to the need 
Citation: Drainoni M, Carey KM, Morgan JR, Christiansen CL, McDoom M M, et al. (2015) An Interrupted Continuum of Care? What are the Risk Factors and Comorbidities Related to Long-Term Engagement and Retention in HIV Care?. J AIDS Clin Res 6: 468. doi:10.4172/21556113.1000468

Page 5 of 6

\begin{tabular}{|c|c|c|c|c|}
\hline \multirow{4}{*}{$\begin{array}{l}\text { Variable } \\
\mathrm{n}=485 \\
\text { Female }\end{array}$} & \multicolumn{2}{|c|}{ Retention } & & \\
\hline & \multirow{3}{*}{$\begin{array}{l}\text { OR } \\
1.00\end{array}$} & \multirow{3}{*}{$\begin{array}{c}\text { p-value } \\
\text { Ref. }\end{array}$} & \multirow{2}{*}{\multicolumn{2}{|c|}{$95 \% \mathrm{Cl}$}} \\
\hline & & & & \\
\hline & & & & \\
\hline Male & 0.84 & 0.51 & 0.50 & 1.41 \\
\hline White & 1.00 & Ref. & & \\
\hline Other/Unknown & 0.55 & 0.47 & 0.11 & 2.81 \\
\hline Black & 1.32 & 0.40 & 0.69 & 2.50 \\
\hline Hispanic & 1.41 & 0.34 & 0.70 & 2.84 \\
\hline Housing & 1.00 & Ref. & & \\
\hline Homeless & 0.43 & 0.02 & 0.21 & 0.89 \\
\hline Unknown Housing & 1.18 & 0.90 & 0.08 & 16.37 \\
\hline Heterosexual & 1.00 & Ref. & & \\
\hline Other Risk & 0.23 & 0.07 & 0.05 & 1.13 \\
\hline Unknown Risk & 0.18 & 0.01 & 0.05 & 0.64 \\
\hline MSM & 1.26 & 0.48 & 0.66 & 2.44 \\
\hline IDU (incl MSM IDU) & 1.10 & 0.79 & 0.55 & 2.23 \\
\hline Age & 1.30 & 0.30 & 0.79 & 2.16 \\
\hline On ART Baseline & 0.99 & 0.26 & 0.97 & 1.01 \\
\hline VL undetectable & 1.00 & Ref. & & \\
\hline VL detectable & 1.20 & 0.62 & 0.57 & 2.52 \\
\hline VL unknown at first visit & 1.12 & 0.82 & 0.43 & 2.89 \\
\hline CD4 over 200 & 1.00 & Ref. & & \\
\hline CD4<200 & 1.67 & 0.16 & 0.81 & 3.41 \\
\hline $\begin{array}{l}\text { CD4 unknown at first } \\
\text { visit }\end{array}$ & 2.09 & 0.07 & 0.94 & 4.65 \\
\hline ADI & 1.36 & 0.56 & 0.49 & 3.83 \\
\hline $\begin{array}{l}\text { Medical Comorbidities } \\
1+\end{array}$ & 0.91 & 0.78 & 0.48 & 1.74 \\
\hline Hepatitis A, B, or C & 0.75 & 0.59 & 0.26 & 2.13 \\
\hline Psychiatric Disorder & 2.65 & 0.01 & 1.27 & 5.51 \\
\hline STI & 1.11 & 0.77 & 0.55 & 2.24 \\
\hline $\begin{array}{l}\text { Substance Use } \\
\text { Disorder }\end{array}$ & 0.54 & 0.20 & 0.22 & 1.37 \\
\hline
\end{tabular}

Table 4: Predictors of Retention in Care $(n=485)$.

for individuals with psychiatric disorders to maintain connection to services in order to maintain their mental health, as well as to the ability of the multidisciplinary medical home model in this clinic (colocated primary care, case management, mental health treatment, and support services) to address their needs. A medical home that includes integrated behavioral health services may be one of the strongest impetuses for patients to continue to return to care.

This study has several limitations. First, it is based on data from a single institution and therefore may not be generalizable. However, the single institution evaluated is of interest as a large urban safety net medical center and the findings may be relevant to other safety net institutions. Second, in order to make comparisons between groups, it was necessary to use only the data available at the baseline visit which meant that a large proportion of CD4 and VL data were unknown, and

some comorbidities may not become apparent until follow-up visits. Third, in using any sample drawn from a health care setting there may be selection bias. Our sample was selected from patients who made an initial clinic visit and this may have underestimated the challenges faced by individuals who cannot even make that initial visit. Finally, as the electronic medical record is from a single institution, it does not allow us to track other locations where patients might receive care. This could lead us to believe that some patients have dropped out of care when they actually have changed their location of care.

Despite these limitations, important knowledge can be gained from this study. We found specific factors that can be identified at an initial clinic visit that are associated with a lack of engagement in care and as well as a lack of retention over time. These findings have important implications for the content of an initial HIV visit and the development of care models, such as the importance of probing related to transmission risk factor, the strength of co-location of mental health and general health care. This investigation has also identified a potentially risky time point on the HIV care continuum, the period of transitions between care sites that has not been previously well-explored. Yet our findings may indicate the need for a special focus when patients are experiencing care disruption in order to assure successful engagement in care. Developing a system at the initial patient visit to thoroughly identify and mitigate factors that put patients at greatest risk for poor engagement and/or retention in care may be an important step, and is consistent with the imperative for the development of the medical home espoused by the Affordable Care Act (ACA) of 2012. The medical home model with the use of a multi-disciplinary team dedicated to addressing behavioral health and case management issues integrated into a primary care clinic has the potential to provide enhanced intake and address needs that may otherwise lead to poor outcomes for individuals at the highest risk. This is also is consistent with findings regarding the value of integrated care for high-risk populations, particularly those with limited social stability [27-30]. Patients with complex psychiatric and social issues may not always view their medical care as a key priority in an otherwise extremely complicated life, particularly if they are feeling well. Having behavioral health care and case management as core services within an HIV clinic may mean that patients are more likely to receive care for both their medical and mental health issues and may motivate such patients to consistently "come home" to effectively address these potentially destabilizing issues, while simultaneously receiving HIVspecific medical services vital for their long term physical health and well-being.

\section{Funding Sources/Disclosures}

Data collection for this study was partially funded by funds from the Retention in Care (RIC) Intervention study, Centers for Disease Control and Prevention and Health Resources and Services Administration [ClinicalTrials.gov: CDCHRSA9272007].

\section{Reference}

1. Gardner EM, McLees MP, Steiner JF, Del Rio C, Burman WJ (2011) The spectrum of engagement in HIV care and its relevance to test-and-treat strategies for prevention of HIV infection. Clin Infect Dis 52: 793-800.

2. Torian LV, Wiewel EW (2011) Continuity of HIV-related medical care, New York City, 2005-2009: Do patients who initiate care stay in care? AIDS Patient Care STDS 25: 79-88

3. Helleberg M, Engsig FN, Kronborg G, Larsen CS, Pedersen G, et al. (2012) Retention in a public healthcare system with free access to treatment: a Danish nationwide HIV cohort study. AIDS 26: 741-748.

4. Yehia BR, Fleishman JA, Metlay JP, Korthuis PT, Agwu AL, et al. (2012) Comparing different measures of retention in outpatient HIV care. AIDS 26 1131-1139. 
Citation: Drainoni M, Carey KM, Morgan JR, Christiansen CL, McDoom M M, et al. (2015) An Interrupted Continuum of Care? What are the Risk Factors and Comorbidities Related to Long-Term Engagement and Retention in HIV Care?. J AIDS Clin Res 6: 468. doi:10.4172/21556113.1000468

Page 6 of 6

5. Cohen SM, Van Handel MM, Branson BM, Blair JM, Hall HI, et al. (2011) Vital Signs: HIV Prevention Through Care and Treatment — United States. Morbidity and Mortality Weekly Report. 60: 1618-1623.

6. Fleishman JA, Yehia BR, Moore RD, Korthuis PT, Gebo KA, et al. (2012) Establishment, retention, and loss to follow-up in outpatient HIV care. Journal of Acquired Immune Deficiency Syndrome 60: 249-259.

7. Hall HI, Gray KM, Tang T, Li J, Shouse L, et al. (2012) Retention in care of adults and adolescents living with HIV in 13 U.S. areas. J Acquir Immune Defic Syndr 60: 77-82.

8. Giordano TP, Visnegarwala F, White AC Jr, Troisi CL, Frankowski RF, et al. (2005) Patients referred to an urban HIV clinic frequently fail to establish care: factors predicting failure. AIDS Care 17: 773-783.

9. Marks G, Gardner LI, Craw J, Crepaz N (2010) Entry and retention in medical care among HIV-diagnosed persons: a meta-analysis. AIDS 24: 2665-2678.

10. Giordano TP, Gifford AL, White AC Jr, Suarez-Almazor ME, Rabeneck L, et al (2007) Retention in care: a challenge to survival with HIV infection. Clin Infect Dis 44: 1493-1499.

11. Mugavero MJ, Amico KR, Westfall AO, Crane HM, Zinski A, et al. (2012). Early retention in HIV care and viral load suppression: implications for a test and treat approach to HIV prevention. Journal of Acquired Immune Deficiency Syndrome 59: 86-93.

12. Werb D, Milloy MJ, Kerr T, Zhang R, Montaner J, et al. (2013) Injection drug use and HIV antiretroviral therapy discontinuation in a Canadian setting. AIDS Behav 17: 68-73

13. Lanoy E, Mary-Krause M, Tattevin P, Dray-Spira R, Duvivier C, et al. (2006) Predictors identified for losses to follow-up among HIV-seropositive patients. J Clin Epidemiol 59: 829-835.

14. Andersen JW, Fass R, van der Horst C (2007) Factors associated with early study discontinuation in AACTG studies, DACS 200. Contemp Clin Trials 28 583-592.

15. Christopoulos KA, Das M, Colfax GN (2011) Linkage and retention in HIV care among men who have sex with men in the United States. Clin Infect Dis 52 Suppl 2: S214-222

16. Marx KA, Malka ES, Ravishankar J, Schwartz RM (2011) Measurement of retention in care among adults infected with HIV in an urban clinic. AIDS Care 23: $1298-1304$.

17. Mugavero MJ, Westfall AO, Zinski A, Davila J, Drainoni M, et al. (2012) Measuring retention in HIV care: the elusive gold standard. J Acquir Immune Defic Syndr 61: 574-580.
18. Gardner EM, Daniloff E, Thrun MW, Reirden DH, Davidson AJ, et al. (2013) Initial linkage and subsequent retention in HIV care for a newly diagnosed HIV infected cohort in Denver, Colorado. J Int Assoc Provid AIDS Care 12: 384-390.

19. Howe CJ, Cole SR, Napravnik S, Eron JJ (2010) Enrollment, retention, and visit attendance in the University of North Carolina Center for AIDS Research HIV Clinical Cohort, 2001-2007. Aids Research and Human Retroviruses 26 : 875-881

20. Mugavero MJ, Davila JA, Nevin CR, Giordano TP (2010) From access to engagement: measuring retention in outpatient HIV clinical care. AIDS Patient Care STDS 24: 607-613.

21. Sherer R, Stieglitz K, Narra J, Jasek J, Green L, et al. (2002) HIV multidisciplinary teams work: support services improve access to and retention in HIV primary care. AIDS Care 14 Suppl 1: S31-44.

22. Gardner LI, Metsch LR, Anderson-Mahoney P, Loughlin AM, del Rio C, et al. (2005) Efficacy of a brief case management intervention to link recently diagnosed HIV-infected persons to care. AIDS 19: 423-431.

23. Messeri PA, Abramson DM, Aidala AA, Lee F, Lee G (2002) The impact of ancillary HIV services on engagement in medical care in New York City. AIDS Care 14 Suppl 1: S15-29.

24. Kidder DP, Wolitski RJ, Campsmith ML, Nakamura GV (2007) Health status health care use, medication use, and medication adherence among homeless and housed people living with HIVIAIDS. Am J Public Health 97: 2238-2245.

25. Baillargeon J, Giordano TP, Rich JD, Wu ZH, Wells K, et al. (2009) Accessing antiretroviral therapy following release from prison. JAMA 301: 848-857.

26. Cabana MD, Jee SH (2004) Does continuity of care improve patient outcomes? J Fam Pract 53: 974-980.

27. Drainoni M, Farrell C, Sorensen-Alawad A, Palmisano JN, Chaisson C, et al. (2014) Patient perspectives of an integrated program of medical care and substance use treatment. AIDS Patient Care STDS 28: 71-81.

28. Rebholz C, Drainoni M, Cabral H (2009) Substance use and social stability among at-risk HIV-infected persons. Journal of Drug Issues 39: 851-870.

29. Magnus M, Schmidt N, Kirkhart K, Schieffelin C, Fuchs N, et al. (2001) Association between ancillary services and clinical and behavioral outcomes among HIV-infected women. AIDS Patient Care STDS 15: 137-145.

30. Ashman JJ, Conviser R, Pounds MB (2002) Associations between HIV-positive individuals' receipt of ancillary services and medical care receipt and retention. AIDS Care 14 Suppl 1: S109-118. 